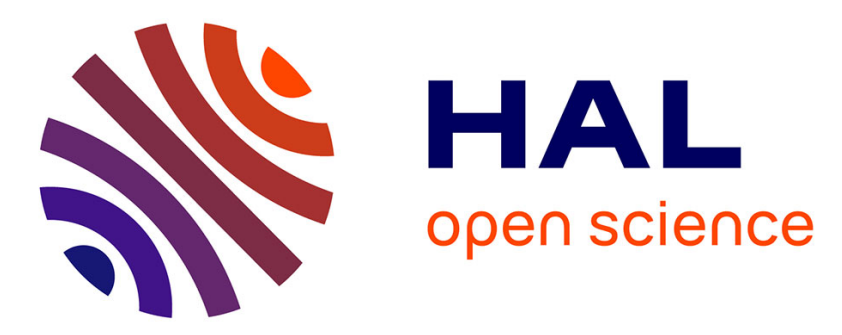

\title{
Capacity of an in vitro rat skin model to predict human dermal absorption: influences of aging and anatomical site
}

Fabrice Marquet, Marie-Christine Grandclaude, Elisabeth Ferrari, Catherine

Champmartin

\section{To cite this version:}

Fabrice Marquet, Marie-Christine Grandclaude, Elisabeth Ferrari, Catherine Champmartin. Capacity of an in vitro rat skin model to predict human dermal absorption: influences of aging and anatomical site. Toxicology in Vitro, 2019, 10.1016/j.tiv.2019.104623 . hal-03028090

\section{HAL Id: hal-03028090 https://hal.science/hal-03028090}

Submitted on 27 Nov 2020

HAL is a multi-disciplinary open access archive for the deposit and dissemination of scientific research documents, whether they are published or not. The documents may come from teaching and research institutions in France or abroad, or from public or private research centers.
L'archive ouverte pluridisciplinaire HAL, est destinée au dépôt et à la diffusion de documents scientifiques de niveau recherche, publiés ou non, émanant des établissements d'enseignement et de recherche français ou étrangers, des laboratoires publics ou privés. 


\title{
Capacity of an in vitro rat skin model to predict human dermal
}

\section{absorption: influences of aging and anatomical site}

Fabrice Marquet*, Marie-Christine Grandclaude, Elisabeth Ferrari and Catherine Champmartin,

Institut National de Recherche et de Sécurité, Rue du Morvan. CS 60027, 54519 Vandœurve

Cedex, France; e-mail : fabrice.marquet@inrs.fr

Fax: $+33(0) 383508515$

Phone: +33 (0)3 83502096

* To whom correspondence should be addressed

\begin{abstract}
In addition to inhalation, dermal absorption is a route of exposure to be considered when assessing occupational risks. To investigate dermal penetration of chemicals, human skin samples are regarded as the gold standard. As human samples can be difficult to obtain, many experiments are performed with rat skins, and the results extrapolated to describe human percutaneous absorption. Here, we examined the characteristics of rat skin samples and compared absorption to that measured with in vitro human skin. The thickness of the stratum corneum layer in rat skin samples was found to be uniform when samples were excised from the animals' backs once they were at least 7-weeks-old. Overall, dorsal skin samples from mature rats could be reliably used to measure the flux of hydrophilic liquid molecules, such as $\mathrm{N}$-methyl-2-pyrrolidone, and N,N-dimethylformamide. In contrast, with a solid lipophilic substance, bisphenol A, dissolved in acetone, the flux obtained with rat skin samples was 3-
\end{abstract}


fold higher than that measured with human skin. Consequently, it does not appear relevant to use rat skin in place of human skin to measure absorption of solid lipophilic substances.

\section{Keywords}

Species specificity; rat; human; in vitro skin permeation; transdermal chemical delivery

\section{Abbreviations}

\section{SC: Stratum Corneum}

NMP: N-methyl-2-pyrrolidone

DMF: N,N-dimethylformamide

BPA: Bisphenol A

TEWL: Transepidermal water loss 


\section{Introduction}

Every day, workers may be exposed to a whole host of chemicals in their occupational environment. Industrial toxicants are mainly absorbed via oral, pulmonary and dermal routes. Among these routes, dermal absorption can be a major route for chemicals because of the large surface area of the human body. The human skin protects the body from physical strain and from exogenous products. Its barrier function is mainly assured by its outermost layer, the stratum corneum (SC). In discussions surrounding prevention policies, there are clear concerns that chemicals might penetrate the SC, and then the viable epidermis, to gain access to the dermis where there are plenty of blood vessels constituting a gateway for entry deeper into the body. SC is a superficial, thin and relatively dry layer of skin. It is composed of dead epidermal cells, the corneocytes, that have lost their nuclei and cytoplasmic organelles (McGrath et al., 2004). Corneocytes are separated by intercellular spaces filled with lipids and an aqueous film, which make up lamellar lipid bilayers (Schneider et al., 2009). The SC is particularly lipid-rich and constitutes the primary barrier against penetration and allows the elimination of endogenous compounds (Mizutani et al., 2009). The lipid composition of the SC differs widely compared to that found in most other biological membranes as it includes practically no phospholipids. Rather, the main components are long-chain ceramides, fatty acids and cholesterol. Although at body-surface temperature, both the lipid and keratin components are solid, in hydrated conditions, minor fractions of the SC lipid and protein components become liquid. This property is expected to change the permeability of the dermal layer. Indeed, the increase in fluidity makes the SC more permeable to both polar and nonpolar compounds, and may influence skin elasticity. Dermal absorption can thus be significantly affected by the external conditions (temperature and humidity) and the nature of the vehicle (used to solubilize solid chemicals) in which the compound is miscible. 
In the experiment described here, we have attempted to reduce the factors modifying dermal absorption as far as possible to compare the percutaneous permeation of three substances which are widely used in occupational environments: two solvents and one solid, lipophilic substance. The first molecule tested was N-methyl-2-pyrrolidone (NMP), which is frequently used to clean surfaces and dissolve lacquers, adhesives and polymer resins. The second molecule was N,N-dimethylformamide (DMF), used in the production of films, acrylic fibers and plastics, in the pharmaceutical industry and in the production of pesticides (Bader et al., 2008; Nomiyama et al., 2001). The third compound was bisphenol A, which is used in the production of epoxy resin and thermal paper.

Skin absorption and dermal delivery of chemicals can be evaluated by in vitro method using excised skin (OECD, 2004a). Skin from human or animal sources can be used. Freshly-excised human skin samples (usually from abdomen or breast) are often regarded as the gold standard in absorption assays (OECD, 2004b; Todo, 2017). However, the supply of human skins from plastic surgery centers is often limited and their quality can be quite unpredictable. As a result, researchers frequently use rodent skins as an alternative to human skin when performing in vitro percutaneous absorption studies. Rats have numerous advantages: they are small and easily available, and there is a large body of data about them. Rat skin shares many structural similarities with human skin (Godin and Touitou, 2007), but the use of a rat model may be inappropriate in some investigations and certain conclusions should only be extrapolated to human skin with caution. The most striking difference between rat and human skin is the fact that rat skin is generally more permeable than human skin (OECD, 2011; Jung and Maibach, 2015). Using 'Triple Pack' approach (i.e. combining data from in vivo animal, in vitro animal in vitro human dermal absorption studies) estimation of human dermal absorption could be improve (OECD, 2011). 
Before assessing a quantitative comparison of skin permeation parameters between human and rat skins, the parameters that might influence dermal absorption on rat skin, and thereby should increase variability of the model must be known and characterized. In the case of the rat, dorsal or ventral skin are the preferential zone but dorsal skin should be used if the study is designed to correspond with the in vivo application site (OECD, 2004b). However, the dorsal zone is not homogeneous according to the age of the animal.

The aim of the present study was thus to determine the ideal age at which skin can be harvested from rats, and the locations from which to excise skin samples so as to reduce the variability of the measurements carried out in this animal model. After determining the relevant age and the location, the absorption fluxes of NMP, DMF and BPA were comparatively assessed in human and rat skin samples. 


\section{Materials and Methods}

\subsection{Animals}

Forty Sprague-Dawley rats (Charles River, 69210 Saint-Germain-Nuelles, France) were used in this study. The animals were maintained on a $12 \mathrm{~h} / 12 \mathrm{~h}$ day/night cycle, at constant temperature and humidity $\left(22 \pm 2{ }^{\circ} \mathrm{C}\right.$ and $50 \pm 15 \%$, respectively) with free access to a commercial rodent diet (food pellets, Scientific animal Food and engineering, Augy, France) and tap water. They were housed in cages $(350 \times 180 \times 184 \mathrm{~mm})$ on irradiated cellulose BCell 8 bedding (ANIBED, Route de Lude, 72510 Pontvallain, France). The animal facilities are fully accredited (C54-547-10), and investigators adhered to the Guide for Care and Use of Laboratory Animals promulgated by the European parliament and council (Directive, 2010/63/EU, 22 September 2010). The protocol for the present study (reference CELMEA-2012-0033) was approved by the local ethics committee.

\subsection{Rat skin procurement}

All the rats studied here were from the same 3-week-old batch. They were euthanatized by intraperitoneal injection of $50 \mathrm{mg} / \mathrm{kg}$ of pentobarbital and were investigated at different ages (4 weeks, 7 weeks, 4, 8 and 12 months). When collecting skin samples, the entire dorsal region was clipped and the subcutaneous tissue carefully removed. Small skin samples (about $0.6 \mathrm{~cm}^{2}$ ) were removed from three different locations (shoulders, mid-back and hips) for histological preparation before measuring the thickness of the skin layers. The remaining skin was then stored at $-80{ }^{\circ} \mathrm{C}$ until required for in vitro experiments.

\subsection{Human skin procurement}

Human skin samples were obtained from patients undergoing abdominal plastic surgery. Patients provided their written informed consent for use of their samples in this study. Samples obtained from three different female donors were investigated (29, 31 and 55 years old). 
Immediately following removal, skin was transported to the laboratory and rinsed with a saline solution. Adipose tissue was dissected off, and small skin samples (about $0.6 \mathrm{~cm}^{2}$ ) were removed to measure skin layer thicknesses. The remaining skin was then stored at $-80{ }^{\circ} \mathrm{C}$ until required for in vitro experiments.

\subsection{Histological preparation}

Both rat and human skin specimens were snap frozen in liquid nitrogen and stored at $-80{ }^{\circ} \mathrm{C}$ before analysis. Frozen sections measuring 7 to $10 \mu \mathrm{m}$ thick were cut with a cryostat (Microm HM560, Microm Microtech, Brignais, France). The specimens were routinely processed for observation under light microscopy. Briefly, they were placed on a glass slide and stained with hematoxylin-eosin-saffron. A Nikon microscope (Eclipse 80i) coupled with image analysis software (Nikon NIS element D) were used to measure the thickness of the different skin layers (stratum corneum, viable epidermis and total epidermis).

\subsection{Test substances}

Radiolabeled N-Methyl-2pyrrolidone (N-Methyl $\left[{ }^{14} \mathrm{C}\right]$-2-pyrrolidone, ${ }^{14} \mathrm{C}-\mathrm{NMP}$ ) and $\mathrm{N}, \mathrm{N}$ dimethylformamide (N,N-dimethylformamide $\left.\left[{ }^{14} \mathrm{C}\right],{ }^{14} \mathrm{C}-\mathrm{DMF}\right)$ were supplied by American Radiolabeled Chemicals, Inc. (Saint Louis, USA). Specific activity was $2.0 \mathrm{GBq} / \mathrm{mmol}$ (55 $\mathrm{mCi} / \mathrm{mmol}$ ) according to the supplier. Radiolabeled bisphenol A ([ring $\left.{ }^{14} \mathrm{C}(\mathrm{U})\right]$-bisphenol A, ${ }^{14}$ C-BPA) was supplied by Moravek Biochemicals, Inc. (California, USA), with a specific activity of $1.85 \mathrm{GBq} / \mathrm{mmol}(50 \mathrm{mCi} / \mathrm{mmol})$ according to the supplier. Radiochemical purities, as determined by the suppliers, were at least $98 \%$. Radiochemical purity was verified by HPLC combined with scintillation counting (Tri-Carb 2900TR, Perkin Elmer, The Netherlands). As recommended by the suppliers, ${ }^{14} \mathrm{C}-\mathrm{NMP}$ and ${ }^{14} \mathrm{C}$-BPA were stored at $-20{ }^{\circ} \mathrm{C},{ }^{14} \mathrm{C}$-DMF at $+4{ }^{\circ} \mathrm{C}$. Unlabeled NMP, DMF and BPA (Sigma-Aldrich Chemie S.a.r.l., Saint-Quentin Fallavier, France) were stored at room temperature. Their chemical purity exceeded 99\% 
according to the suppliers. Working solutions were prepared the day before deposition on skin samples by weighing labeled, unlabeled substances, and acetone on a precision balance. The balance is regularly verified as part of a quality assurance process. Liquid scintillation was also used to determine the radiochemical concentration of triplicate samples of the solution administered. The partition coefficients ( $\log \mathrm{K}_{\mathrm{o} / \mathrm{w}}$ ) for DMF, NMP and BPA were -1.01, - 0.38 and 3.32, respectively.

\subsection{In vitro experiments}

In vitro absorption through rat and human skin was assessed in Franz diffusion cells (Bercauverre, Lyon, France), which have a diffusion area of $0.45 \mathrm{~cm}^{2}$ and a receiver volume of $2 \mathrm{~mL}$. The skin was cut using an electric dermatome (Zimmer, Etupes, France). Skin thickness was measured using a plate thickness gauge. Skin samples were placed in diffusion cells with the SC facing up. The dermis side was in contact with the receiver fluid (RPMI 1640, $2.5 \%$ penicillin-streptomycin, $0.2 \%$ gentamycin, $2 \% \mathrm{BSA}$ added for BPA experiments) throughout the experiment. The receiver fluid was continuously stirred with a Teflon-coated magnetic stirrer. Diffusion cells were maintained at a temperature of $36{ }^{\circ} \mathrm{C}$ in a circulating water bath. As a result, the skin surface temperature was $32 \pm 1^{\circ} \mathrm{C}$. The integrity of each skin sample was assessed by measuring transepidermal water loss (TEWL, Tewameter ${ }^{\circledR}$ TM300 Courage + Khazaka, Monaderm, Monaco). $\left[{ }^{14} \mathrm{C}\right]-\mathrm{NMP}\left(40 \mu \mathrm{L} / \mathrm{cm}^{2}\right),\left[{ }^{14} \mathrm{C}\right]-\mathrm{DMF}\left(400 \mu \mathrm{L} / \mathrm{cm}^{2}\right)$ or $\left[{ }^{14} \mathrm{C}\right]-$ BPA solubilized in acetone $\left(50 \mu \mathrm{L} / \mathrm{cm}^{2}, 200 \mu \mathrm{g} / \mathrm{cm}^{2}\right)$ were applied to rat and human skin samples. An aliquot of receiver fluid was collected at regular intervals during the exposure period ( $6 \mathrm{~h}, 24 \mathrm{~h}$ and $48 \mathrm{~h}$ for NMP, DMF and BPA, respectively) using an automatic fraction collector (Gilson GX-281, Middleton USA). An equivalent volume of fresh solution was added to the receiver compartment to maintain a constant volume.

\subsection{Statistical analysis}


Two different analyses were run in this study. Firstly, Stata 14.0 software was used to establish a mixed linear regression for the thicknesses of the SC, viable epidermis, and total epidermis, with "age" and "location" as fixed effects, and their interaction; a random intercept "rat" was included. If the interaction was significant, the simple effect of "location" was tested for each "age". The statistical analyses of data obtained from samples excised from the back, hips and shoulders are detailed throughout the paper.

To compare the human and rat layer thicknesses, a "group" variable was constructed, with modalities including different age groups for the rats, and a single human group.

A second mixed linear regression model (stratum corneum thickness, viable epidermis thickness and total epidermis thickness) was independently applied with a fixed "group" effect, including a random intercept "subject" (human id or rat id).

Secondly, Statgraphics Centurion software version XVI was used to perform statistical analyses on the fluxes. Either a one-way or a two-way ANOVA was run to test the significance of variations as a function of the experimental conditions. Statistical results were expressed as follows: $[\mathrm{F}(\mathrm{dfb}, \mathrm{dfi})=\mathrm{F}$; $\mathrm{p}=\mathrm{value}]$, where $\mathrm{dfb}$ is the number of degrees of freedom between groups, and dfi is the number of degrees of freedom within a group. The F-ratio is the mean squares value between groups divided by the mean squares value within a group. Post hoc analysis was performed by the Bonferroni method.

The threshold for statistical significance was set at 5\%, whatever the statistical analyses carried out. 


\section{Results}

\subsection{SC thickness depends on age and location}

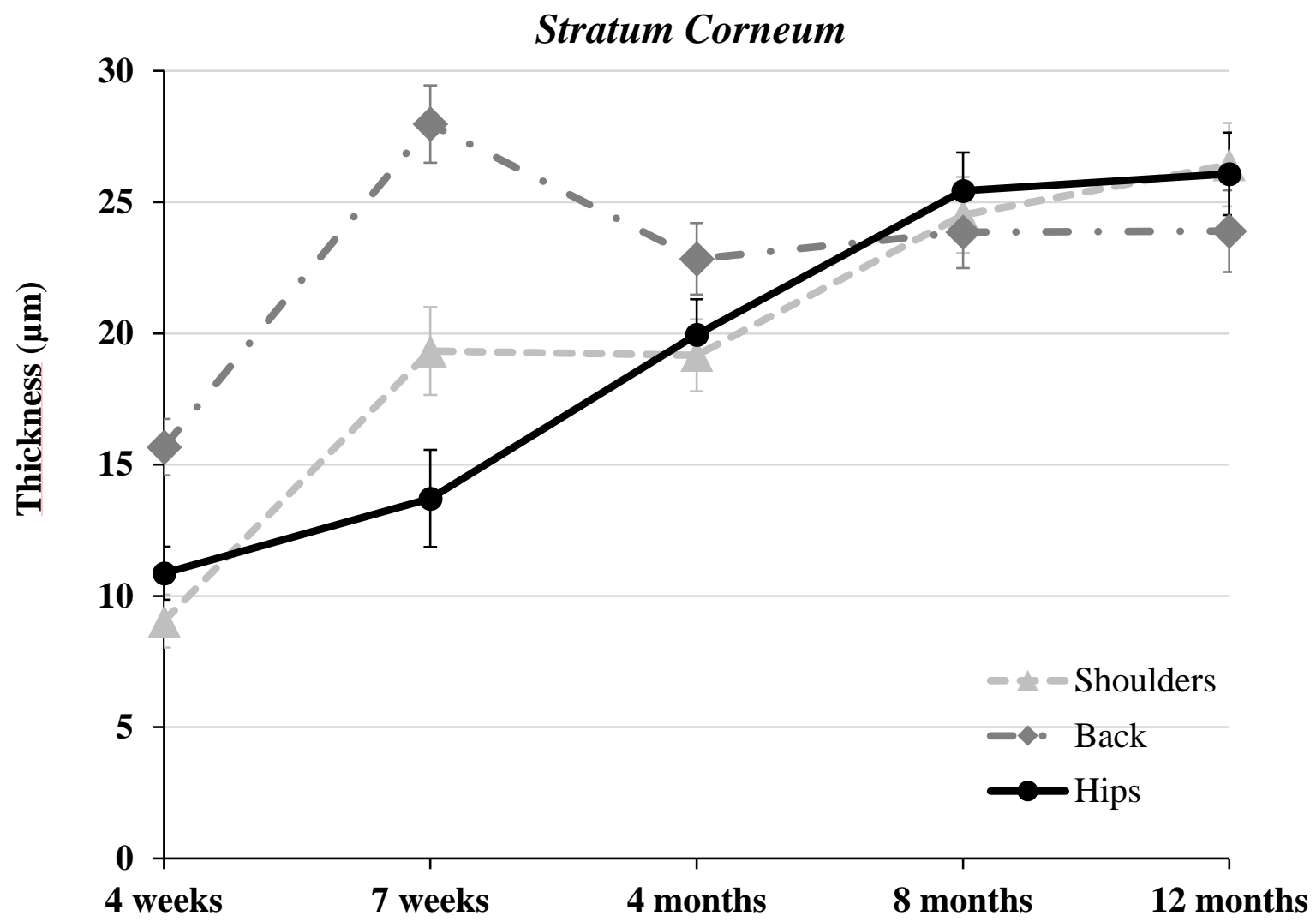

Figure 1: Stratum corneum thickness as a function of age and localization in the SpragueDawley rat.

The SC thickness was measured in skin samples harvested from animals aged between 4 weeks and 12 months (Figure 1). A major change was observed between 4 and 7 weeks $(\mathrm{p}<0.001$, contrast $=-12.30$ ). When examining samples from the different localizations, the thickness of the SC from the samples excised from the hips and shoulders was seen to rise steadily over the first 8 months of life, increasing from 11 to $25 \mu \mathrm{m}$. The increase in thickness was faster for skin from the back, which reached a plateau of approximately $23 \mu \mathrm{m}$ at just 7 weeks (NS, p=0.99, contrast $=-0.64 \pm 2.14)$. Statistically, there was no difference between the thicknesses measured in skin harvested from the backs of rats between 7 weeks and 12 months. 


\subsection{Comparing SC thickness between human and rat skin samples}

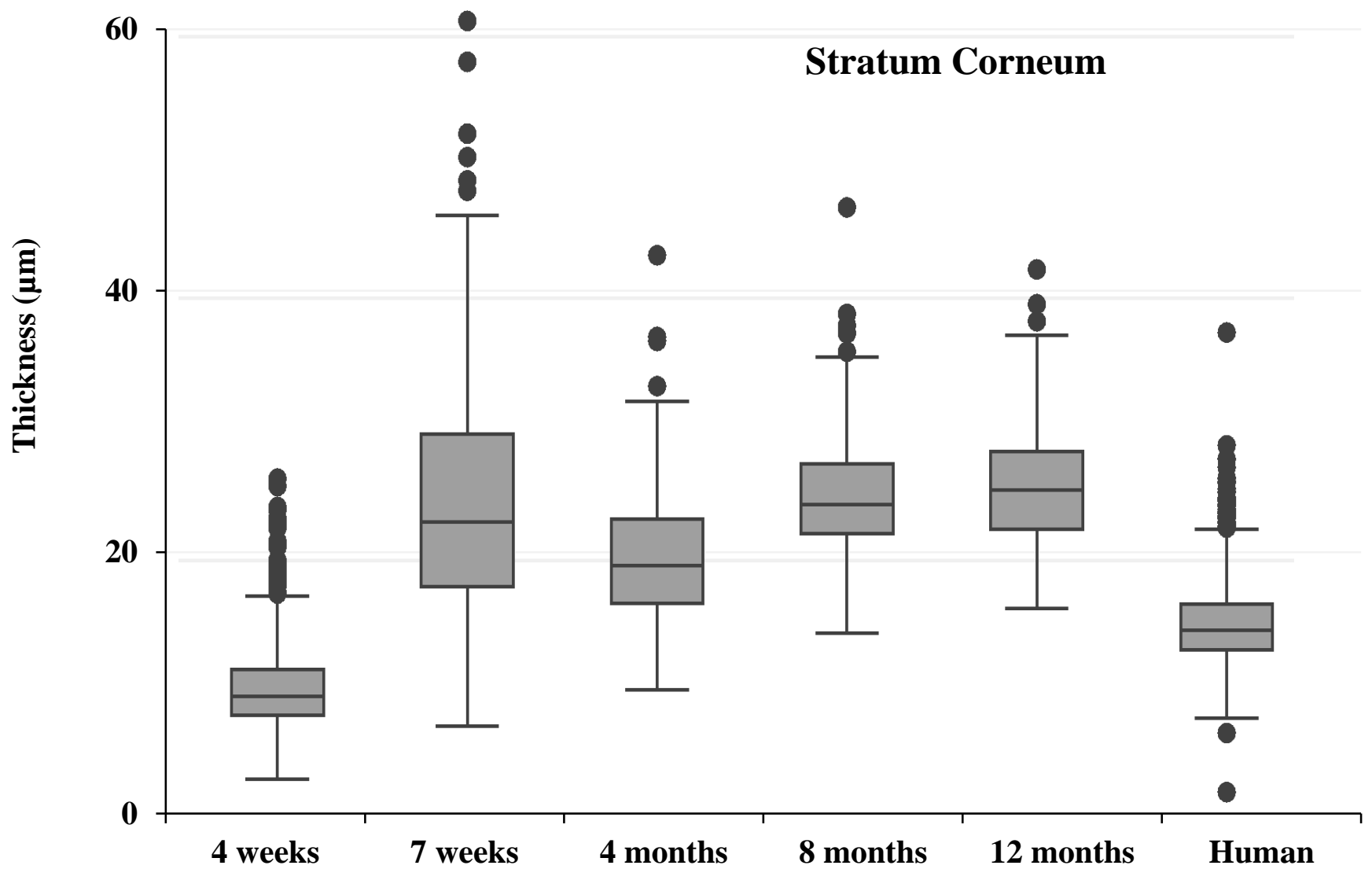

Figure 2: Comparison between stratum corneum thicknesses in human skin samples and in samples from rats at various ages.

The SC thicknesses measured for human and rat skin samples were compared (Figure 2). This comparison revealed that, samples harvested from 4-week-old animals were had a thickness similar to that measured in humans $(16-18 \mu \mathrm{m})(\mathrm{p}<0.001$, contrast $=-5.41 \pm 1.19)$. 


\subsection{Viable epidermis thickness depends on age}

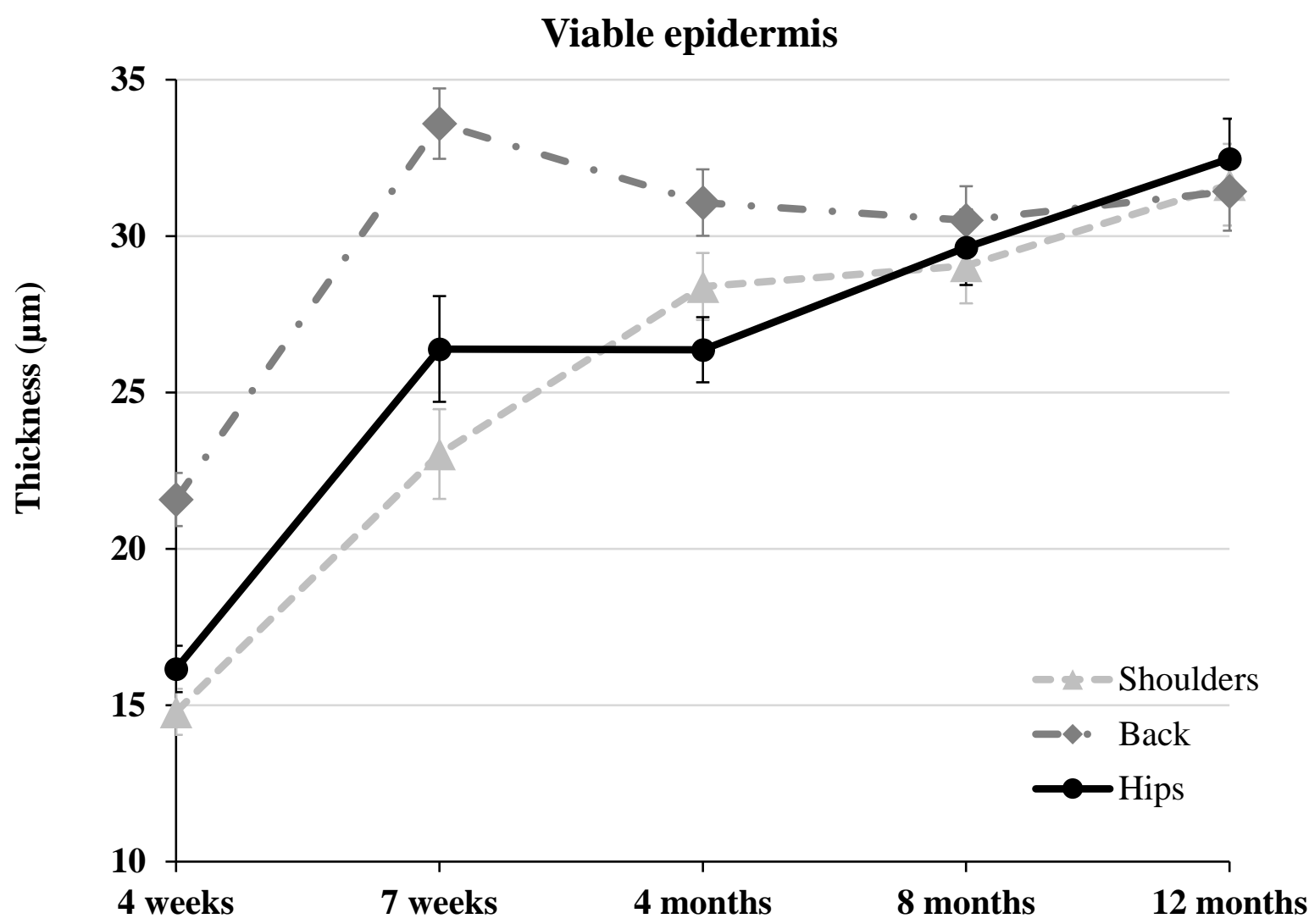

Figure 3: Viable epidermis thickness as a function of age and localization in the SpragueDawley rat.

The thickness of viable epidermis was determined by calculating the difference between the SC and the total epidermal thickness. As above, the thickness of the viable epidermis was relatively uniform (approximately $33 \mu \mathrm{m}$ ) from 7 weeks to 12 months for the samples obtained from the back (Figure 3). Once again, there was no significant difference in the thicknesses measured for samples excised from the back between 7 weeks and 12 months (NS, contrast $=0.56 \pm 1.52$ ). In contrast, the thicknesses of the viable epidermis increased over the period of analysis for samples obtained from hips and shoulders, (from 25 to $32 \mu \mathrm{m}$ between 7 weeks and 12 months). 


\subsection{Total epidermal thickness as a function of age}

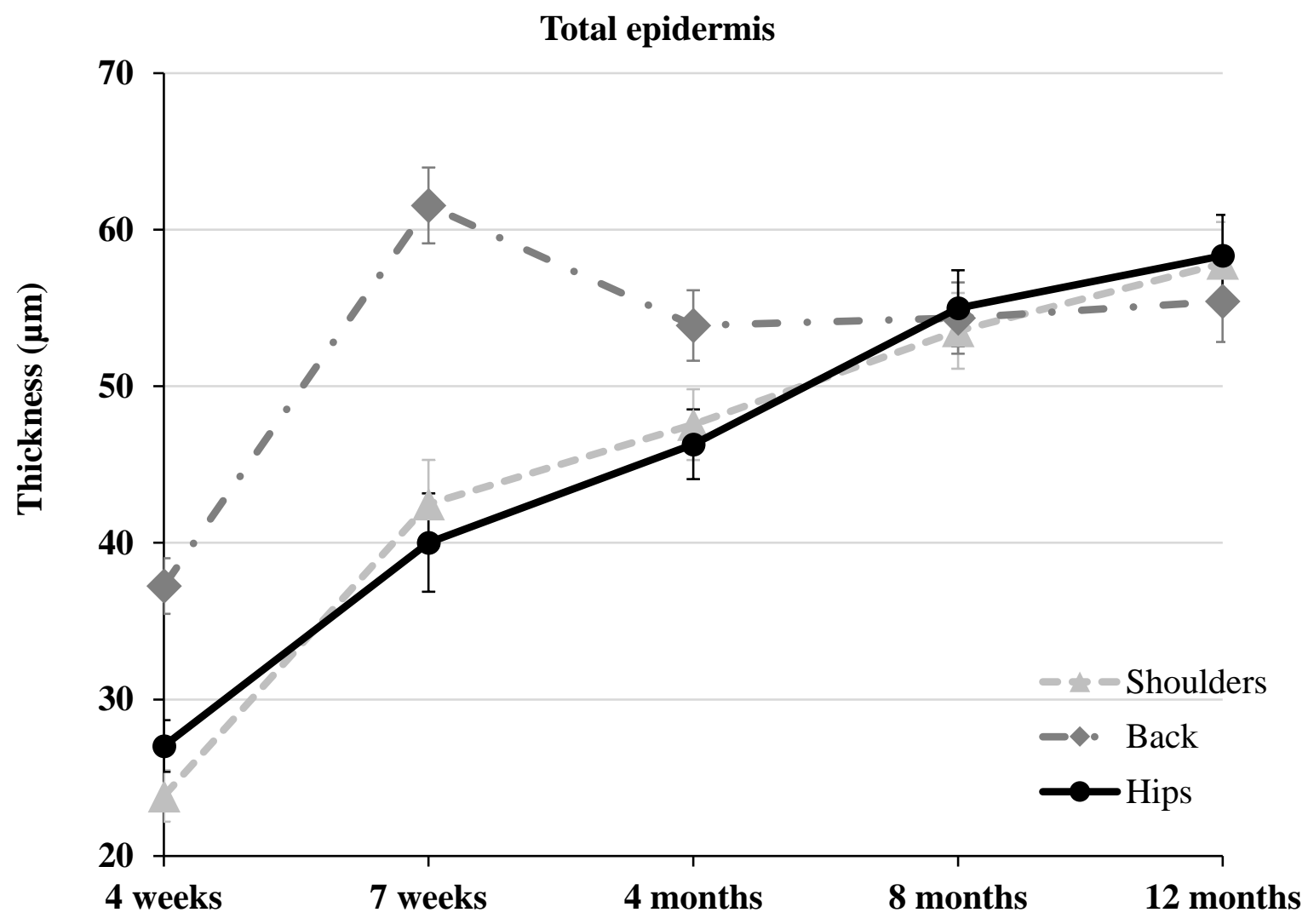

Figure 4: Total epidermis thickness as a function of age and localization in the Sprague-Dawley rat.

The thickness of the total epidermis as a function of age showed similar trends to those observed for the SC. This result was expected, as the total epidermis includes the SC and the viable epidermis. Skin samples excised from the backs of rats were relatively constant in thickness from 7 weeks of age (approximately $55 \mu \mathrm{m}$ ). Indeed, no significant difference was obtained between 7 weeks and 12 months (NS, contrast $=-0.48 \pm 3.20$ ), whereas an overall increase ranging from 40 to $55 \mu \mathrm{m}$ was observed over the full 12 months of analyses. 


\subsection{Histological analyses}

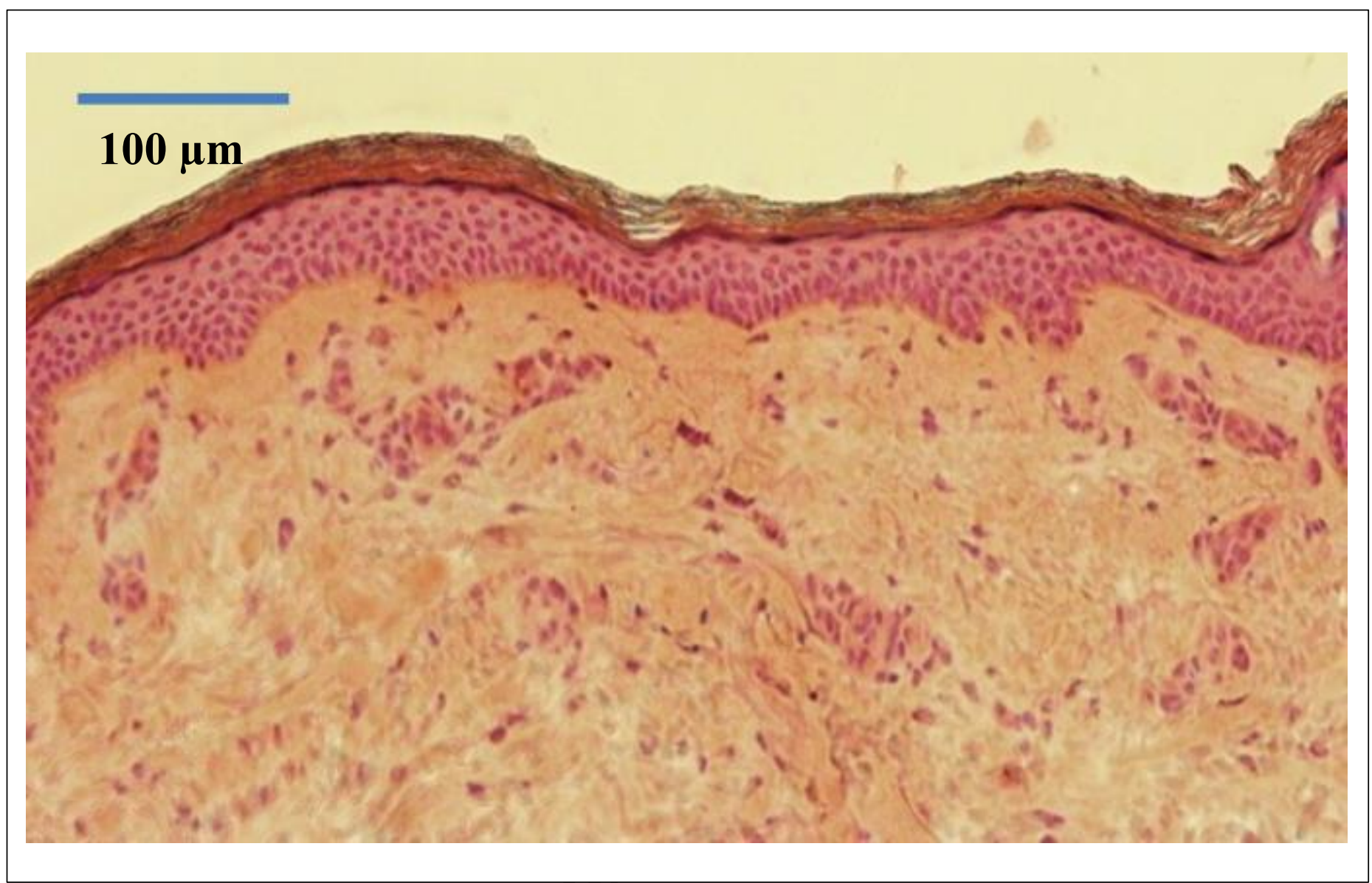

Figure 5(a): Skin layers in an in vitro skin sample from a 40-year-old white European (hematoxylin and eosin staining). Below the stratum corneum, the viable epidermis is composed of living skin cells, or keratinocytes. The thickness of the viable layer can vary from 40 to $100 \mu \mathrm{m}$ depending on the location from which the skin sample was taken. All skin samples were dermatomed to obtain a thickness of $500 \mu \mathrm{m}$. 


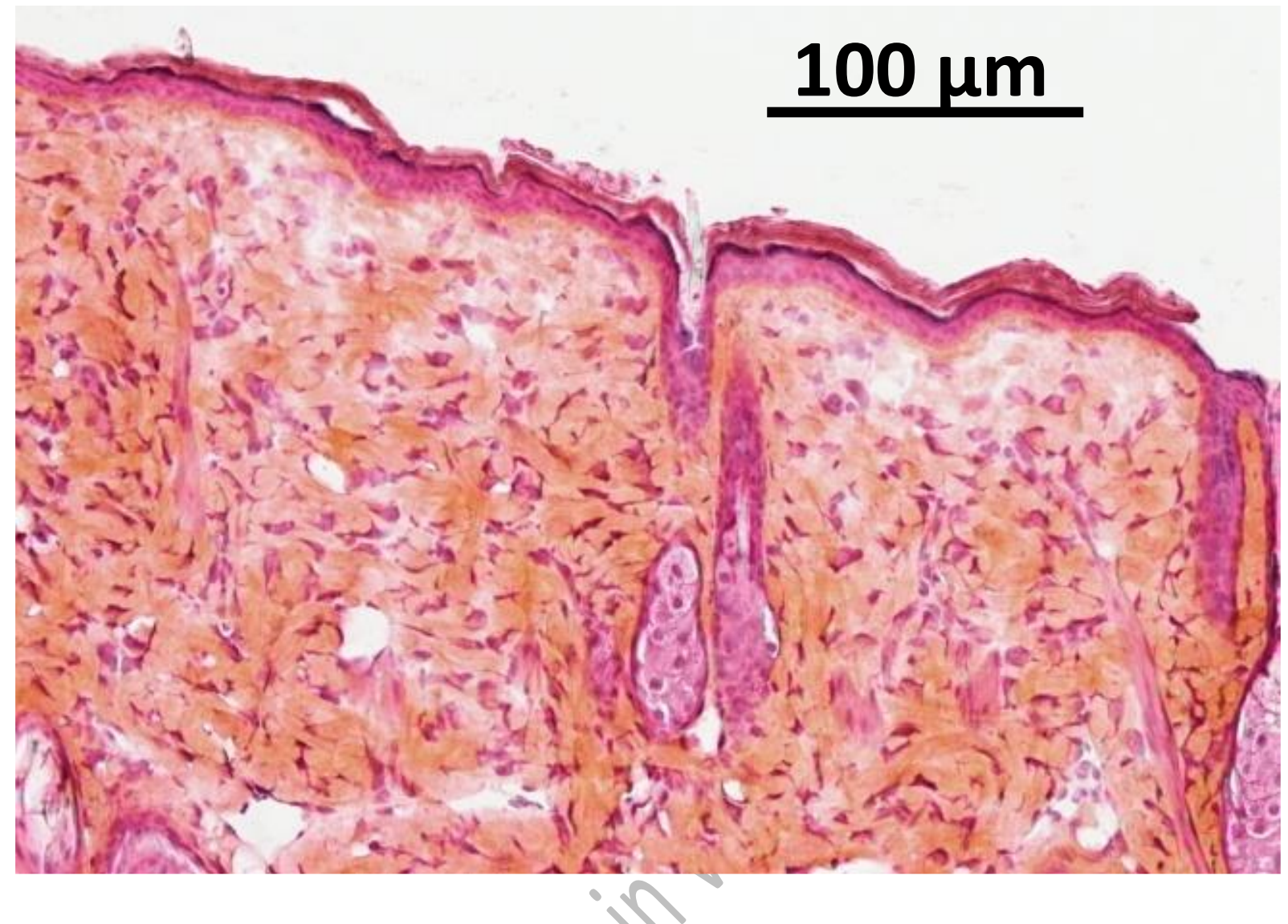

Figure 5(b): Skin layers in rat skin excised from the back of the animal (hematoxylin and eosin stain). Below the stratum corneum, the viable epidermis is composed of living skin cells, or keratinocytes. Several hair follicles are clearly visible. All skin samples were dermatomed to obtain a thickness of $500 \mu \mathrm{m}$.

Standard histological staining (hematoxylin-eosin-saffron) was used to visualize the different skin layers, Although the thicknesses of the different layers changed as rats aged, no difference in skin composition was observed. 


\subsection{Cumulative and absorption fluxes over time}

\subsubsection{Transepidermal water loss}

$\underline{\text { Table } 1}$ Transepidermal water loss measurement of the skin excised samples in rat and human

\begin{tabular}{|c|c|c|}
\hline & Rat & Human \\
\hline NMP & $3.2 \pm 0.8$ & $4.7 \pm 1.4$ \\
\hline DMF & $2.6 \pm 0.4$ & $3.0 \pm 0.4$ \\
\hline BPA & $3.4 \pm 1.8$ & $3.8 \pm 1.3$ \\
\hline
\end{tabular}

Values are expressed in $\mathrm{g} \cdot \mathrm{h}^{-1} \cdot \mathrm{m}^{-2} \pm \mathrm{SD}($ mean $\pm \mathrm{SD})$. TEWL was measured before the exposure on each sample after an equilibrium period of at least 1 hour. The obtained values were quite similar in rat and human for the three tested substances and in accordance with those reported in human by Kottner et al. (2013). TEWL values were all below the $10 \mathrm{~g} \cdot \mathrm{h}^{-1} \cdot \mathrm{m}^{-2}$ limit (Guth et al., 2015). 


\subsection{2 ${ }^{14} \mathrm{C}$ N-methyl-2-pyrrolidone}

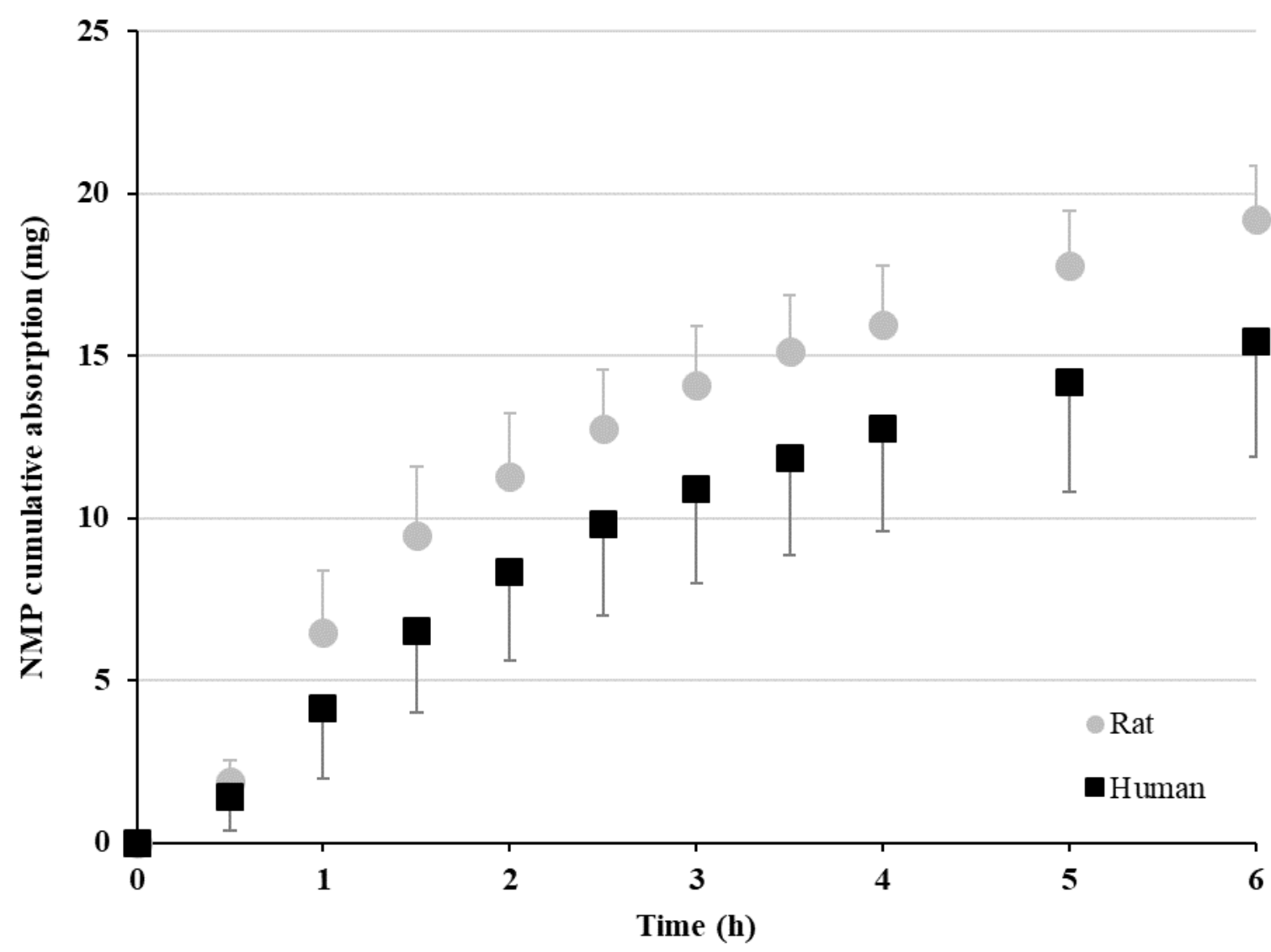

Figure 6(a): Time course for cumulative $\left[{ }^{14} \mathrm{C}\right]-\mathrm{N}$-methyl-2-pyrrolidone absorption after topical application to in vitro human and rat skin samples. Rat samples were excised from the back of animals aged at least 7 weeks old; all human skin samples were from adult donors.

In vitro cumulative percutaneous absorption of neat $\left[{ }^{14} \mathrm{C}\right]-\mathrm{NMP}\left(40 \mu \mathrm{L} / \mathrm{cm}^{2}\right)$ was measured as a function of time with human $(n=3)$ and rat $(n=4)$ skin samples (Figure 6). For rat samples, animals were at least 7 -weeks-old at the time of harvesting. An obvious time $[F(76,10)=48.90$ $\mathrm{p}<0.001]$ and species effect $[\mathrm{F}(76,1)=28.07 \mathrm{p}<0.001]$ was observed. The profiles for cumulative absorption were quite similar between human and rat samples, although there was a clear difference between the two species after one hour $(3.67 \pm 2.31$ between 30 min and 1 hour). The difference increased, reaching its peak at 6 hours. 


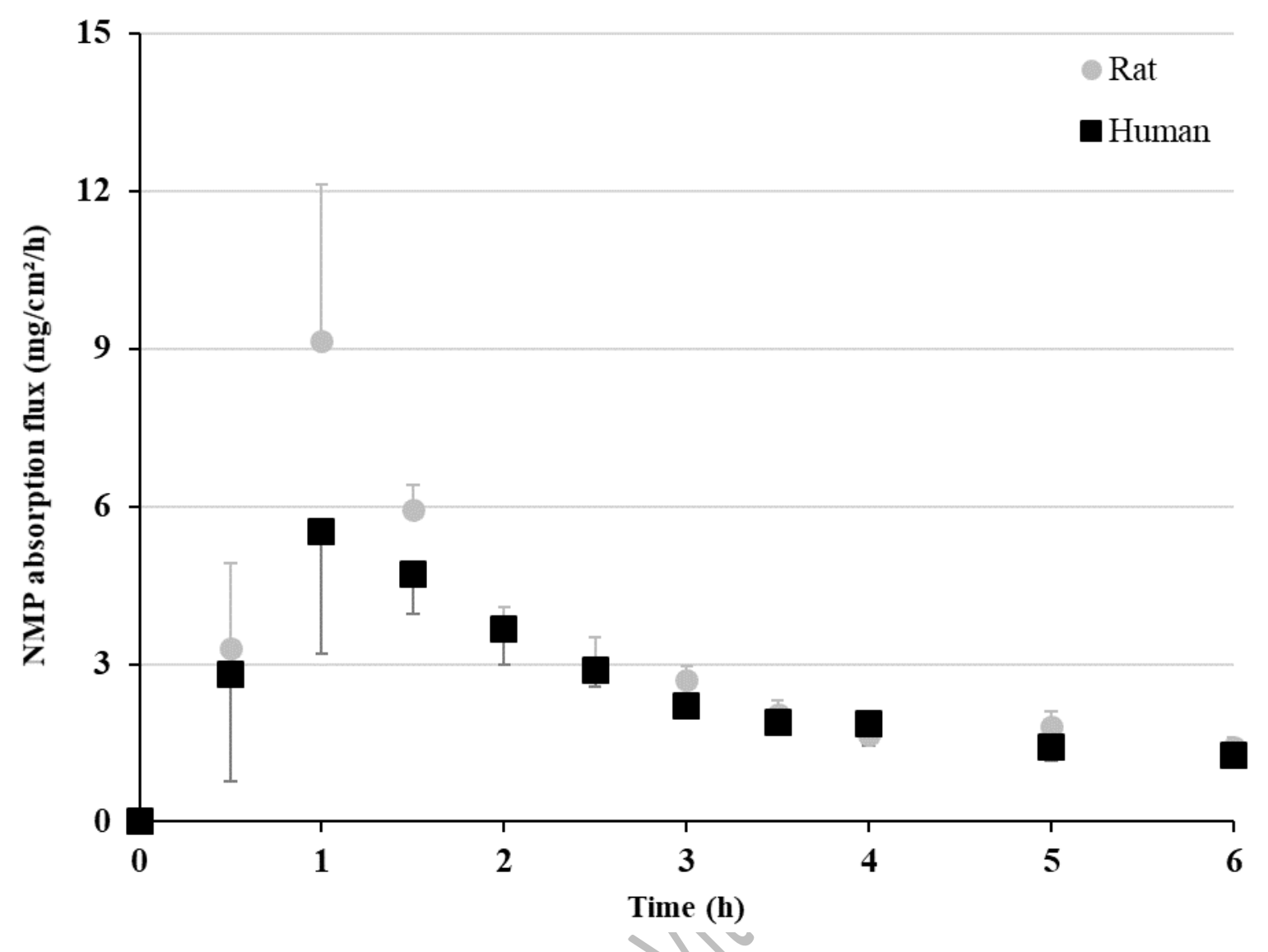

Figure 6(b): Time course of $\left[{ }^{14} \mathrm{C}\right]-\mathrm{N}$-methyl-2-pyrrolidone absorption flux after topical application to in vitro human and rat skin samples. Rat skin samples were excised from the backs of animals aged at least 7 weeks old, whereas the human skin samples were all from adult donors.

The absorption flux for neat $\left[{ }^{14} \mathrm{C}\right]-\mathrm{NMP}\left(40 \mu \mathrm{L} / \mathrm{cm}^{2}\right)$ was calculated from the cumulative percutaneous absorption curve as a function of time (Figure $6 \mathrm{~b}$ ). The patterns of the curves were quite similar, although the absorption fluxes were consistently higher for rat skin than for human skin samples. An obvious time $[F(76,10)=26.03 \mathrm{p}<0.001]$ and species effect $[F(76,1)=5.95 \mathrm{p}<0.02]$ was observed. As expected, both curves peaked after one hour of 
exposure $(4.29 \pm 1.12$ between $30 \mathrm{~min}$ and $1 \mathrm{~h})$. The fluxes peaked at approximately 6 and 9 $\mathrm{mg} / \mathrm{cm}^{2} / \mathrm{h}$ in human and rat, respectively.

\subsection{3 ${ }^{14} \mathrm{C}$ N,N-dimethylformamide}

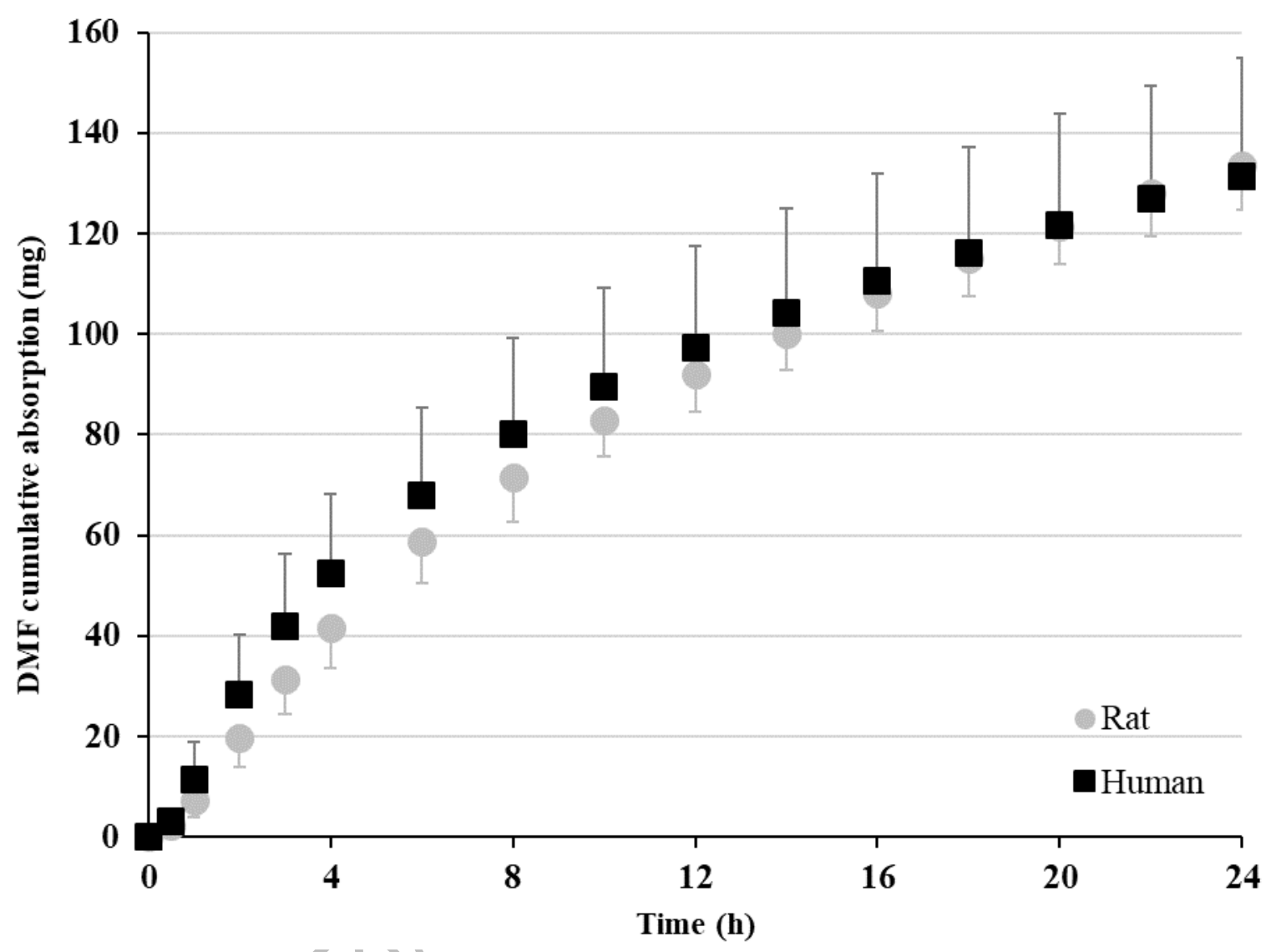

Figure 7(a): Time course of $\left[{ }^{14} \mathrm{C}\right]-\mathrm{N}, \mathrm{N}$-dimethylformamide cumulative absorption. Rat skin samples were excised from the backs of animals aged at least 7 weeks old, whereas human skin samples were all from adult donors.

In vitro cumulative percutaneous absorption of neat $\left[{ }^{14} \mathrm{C}\right]-\mathrm{N}, \mathrm{N}$-dimethylformamide (400 $\left.\mu \mathrm{L} / \mathrm{cm}^{2}\right)$ was measured as a function of time for adult human skin $(\mathrm{n}=3)$ and skin from rats aged at least 7 weeks $(n=4)$ (Figure $7 a)$. An obvious time effect $[F(111,15)=95.18 p<0.001]$ was observed with this compound, whereas the species effect was insignificant $[F(111,1)=3.28$ $\mathrm{p}=0.07]$. The profiles of the human and rat curves were quite similar. 


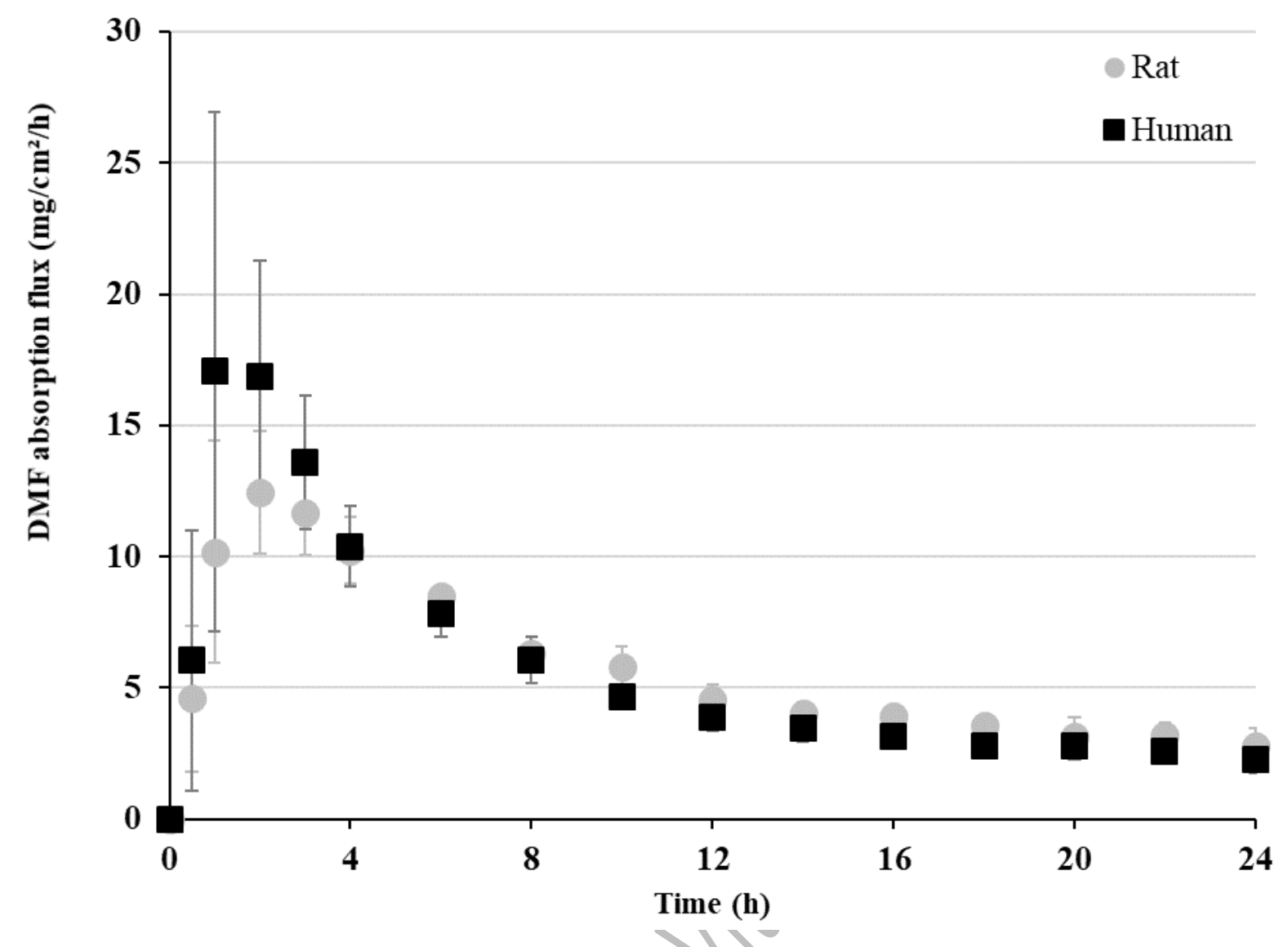

Figure 7(b): Time course of $\left[{ }^{14} \mathrm{C}\right]-\mathrm{N}, \mathrm{N}$-dimethylformamide absorption flux after topical application to in vitro human and rat skin samples. Rat skin samples were excised from the backs of animals aged at least 7 weeks old, whereas human skin samples were all from adult donors.

As for NMP, the in vitro absorption flux of neat [14C]-DMF $\left(400 \mu \mathrm{L} / \mathrm{cm}^{2}\right)$ was measured as a function of time for human $(n=3)$ and rats $(n=6)$ skin. An obvious time effect $[F(111,15)=25.07$ $\mathrm{p}<0.001]$ was observed, whereas the species effect was insignificant $[F(111,1)=1.44 \mathrm{p}=0.23]$. Once again, the profiles of the human and rat curves were quite similar, although a nonsignificant difference was observed up to 4 hours (Figure 7b). The peaks for absorption with human skin was reached after three hours of exposure, whereas with rat skin, the peak was attained at 2 hours. 


\subsection{4 ${ }^{14} \mathrm{C}$ Bisphenol A}

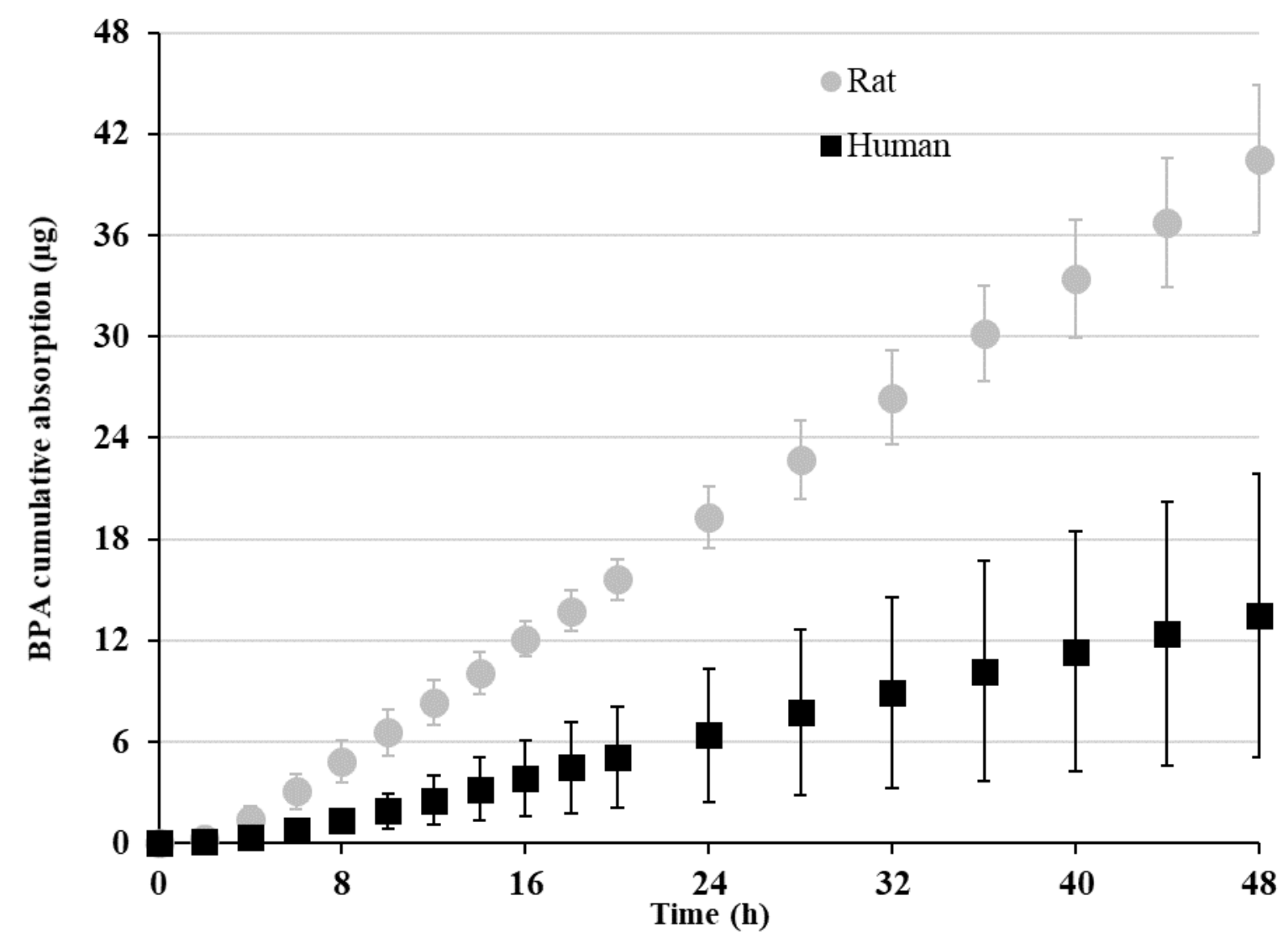

Figure 8(a): $\left[{ }^{14} \mathrm{C}\right]-$ Bisphenol A (BPA) cumulative absorption as a function of time. Comparison between adult rat and human skins. Skin samples were excised from the backs of rats. The animals were aged at least seven weeks at the time of excision.

In vitro cumulative percutaneous absorption of solubilized $\left[{ }^{14} \mathrm{C}\right]-$ Bisphenol A $\left(200 \mu \mathrm{g} / \mathrm{cm}^{2}\right.$, $50 \mu \mathrm{L}$ acetone $\left(\mathrm{cm}^{2}\right)$ was measured as a function of time in adult human skin $(\mathrm{n}=3)$ and skin from rats aged of at least 7 weeks $(n=4)$ (Figure $8 a)$. Obvious time $[F(125,17)=53.03 p<0.001]$ and species effects $[F(125,1)=350.17 \mathrm{p}<0.001]$ were observed. 


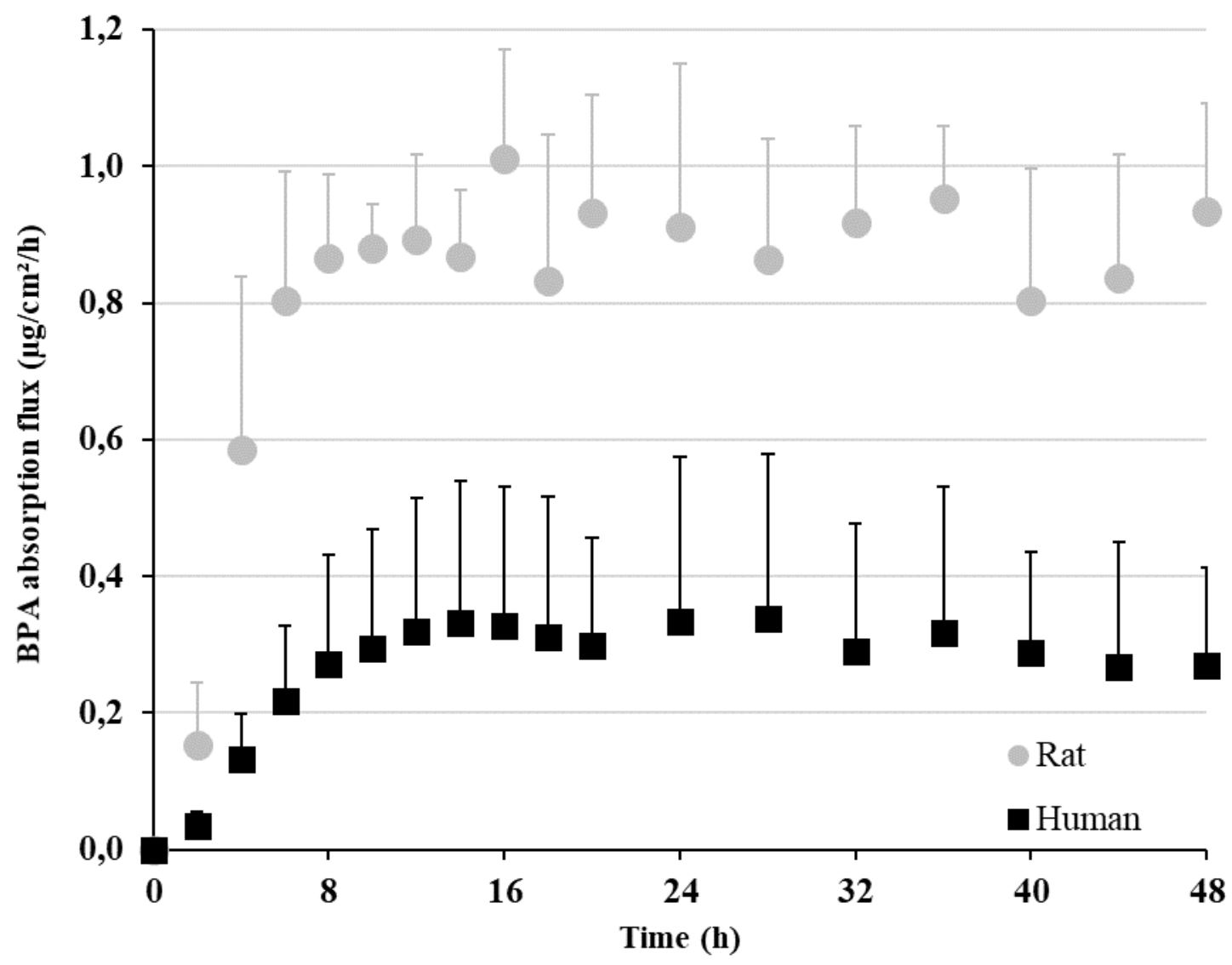

Figure 8(b): Time course of the $\left[{ }^{14} \mathrm{C}\right]$-Bisphenol A (BPA) absorption flux. Skin samples were excised from the backs of rats. The animals were aged at least seven weeks at the time of excision, whereas human skin samples were all from adult donors.

With BPA, there was an approximately 3-fold difference between the fluxes measured with rat skin and those measured with human skin samples (Figure $8 b$ ). The time $[\mathrm{F}(125,17)=8.39$, $\mathrm{p}<0.001]$ and species effects $[\mathrm{F}(125,1)=304.7, \mathrm{p}<0.001]$ were significant. The difference between species emerged after 6 hours $(0.51 \pm 0.06)$. The curves for both species reached a plateau after 12 hours' exposure in acetone $(0.60 \pm 0.06)$. 


\section{Discussion}

The thickness of rat skin samples depends both on the age of animals and on the anatomical sites from which samples were collected. Both the thickness of the SC and that of the total epidermis were relatively constant when the skin was excised from the back of rats aged at least seven weeks. Indeed, after seven weeks, the SC and the total epidermis plateaued at 23 and $55 \mu \mathrm{m}$, respectively, although a significant peak was measured at 7 weeks. The thicknesses of human SCs measured here were similar to those reported by Todo (2017) and Jung \& Maibach (2015): $18 \mu \mathrm{m}$. However, these authors also reported an 18- $\mu \mathrm{m}$ thickness for the rat SC, whereas we found an average thickness of $16 \mu \mathrm{m}$ at 4 weeks for the samples from the back and $23 \mu \mathrm{m}$ from the age of 7 weeks, for all samples, regardless of the location of the excision. The difference between our measurements and those reported in the literature are probably due to the authors using young rats and indicating an average thickness for the SC. However, we cannot confirm this hypothesis as the age of the rat was not mentioned in these previous articles. We consider that reaching the plateau of thickness for the morphological layers corresponds to a certain state of maturation. Although the thickness of the SC measured at 4 weeks was closer to that measured in human skin $(16$ vs. $18 \mu \mathrm{m})$, this layer is not yet fully mature and its thickness increased rapidly up to $23 \mu \mathrm{m}$ from 7 weeks of age (Figure 2). Therefore, we considered it preferable to investigate skin samples with a constant thickness rather than using immature samples even if their thickness was comparable to that of human skin samples. Indeed, steady morphological characteristics of the skin should reduce the variability of the data obtained with the rat model, and that was the purpose behind this study. Skin samples excised from the backs of animals were the first to reach a steady thickness. As a result, skin samples excised from the back of the Sprague-Dawley rat were preferred to those collected from the hips or shoulders. By using these samples, the variability of data from absorption assays should be reduced. 
Beyond the morphological aspects of skins samples, we compared dermal absorption as cumulative absorption and absorption flux - for three test-molecules. Two of the molecules tested were liquid hydrophilic substances: N-methyl-2-pyrrolidone (NMP) was tested at a moderate volume (40 $\mu \mathrm{L} / \mathrm{cm}^{2}$ ), whereas $\mathrm{N}, \mathrm{N}$-dimethylformamide (DMF) was tested at a large volume (400 $\left.\mu \mathrm{L} / \mathrm{cm}^{2}\right)$. The toxicokinetic data and the metabolism of these two molecules have been extensively studied in the laboratory (Payan et al., 2002, 2003). The third molecule: bisphenol A (BPA) was a solid lipophilic molecule which was solubilized in acetone as a vehicle before performing absorption assays.

Overall, with the two liquid hydrophilic molecules (NMP, DMF), the profiles of the curves representing the absorption fluxes and the cumulative absorption were quite similar with rat and human samples. Nevertheless, dermal absorption was significantly greater with rat skin compared to human skin. This difference between rat and human skins was mainly concentrated during the peak of absorption, the duration of which can vary from 3 to 9 hours. Whatever the duration of the peak, rat skins absorbed greater amounts of the chemical compounds than human samples. This interspecies difference could be explained by the fact that rat skin has a higher density of hair follicles than human skin (Bronaugh et al., 1982), and the number of follicles could affect percutaneous absorption of chemicals (Jung and Maibach, 2015). However, as the profiles for the comparative curves for NMP and DMF were quite similar it still seems to be relevant to use rat skin to predict human absorption.

The large difference between the two species found when testing bisphenol A absorption is more worrying. After dissolution in a widely used vehicle, acetone, the flux obtained with rat skin samples was much higher than that measured with human skin (Figure 8b). The reasons for such a difference may be plural. Firstly, as mentioned above, the density of the hair follicles could provide a possible explanation. Secondly, the vehicle could be partly responsible for the difference. Indeed, the SC is the outmost layer of the skin, and as such represents the skin's first 
line of defense. Since the SC is made of a multilamellar lipid matrix, the vehicle could affect the SC barrier in rat or human skin samples differently, modifying its permeability to the toxicants. Topical solvent treatment has been shown to disrupt the cutaneous permeability barrier differently depending on the nature and thickness of the barrier (Grubauer et al., 1987). Moreover, studies suggested that increased water loss can occur following barrier disruption, leading to focal changes in the concentration of inorganic ions on the outer epidermis (Lee et al., 1994). Following acetone-mediated disruption of the barrier, a large variety of homeostatic repair responses can trigger a cascade of metabolic events in the epidermis in an attempt to normalize barrier function. These responses could be different in rats and humans, potentially modifying flux measurements, as the results presented here indicate. Finally, the water content (rather than the relative humidity), due to uncertainties associated with the equilibration of samples containing solvents, could also produce differences in dermal permeation (Pham et al., 2016). Faced with this large difference between rat and human permeation for BPA, a solid lipophilic chemical, we performed the same experiments with artificial sebum as a substitute for acetone. Unfortunately, the same difference in BPA absorption was measured between rat and human permeations. In another study, we tested the percutaneous absorption fluxes of benzo[a]pyrene $(\mathrm{BaP})$, another lipophilic molecule, and a similar large difference between rat and human skin was found (Champmartin et al., 2016). Consequently, when attempting to predict human skin permeation of solid lipophilic toxicants, human skin samples should be preferred to rat skins whenever possible.

\section{Conclusions}

In vitro human skin is regarded as the gold standard when testing dermal absorption for occupational toxicology. Excised human skin samples are always obtained from adult patients. Here, we determined the age and location from which skin samples should be excises so as to reduce inter-sample variability of absorption data. Rat skin should be excised from the backs 
of animals aged at least 7-weeks-old to obtain samples with constant morphological characteristics. Samples excised from the hips or shoulders only reach a steady thickness from 8 months.

Based on our experimental results, the absorption profiles as a function of time and the absorption fluxes were quite similar between rat and human samples for NMP and DMF, two liquid hydrophilic molecules which are considered representative of solvents widely used in factories. In contrast, although the patterns of the curves obtained with rat and human skin were comparable for BPA, the absorption values measured with rat skin samples were almost 3-fold those measured with human skin. Such a considerable difference in result range points out the limits of the rat skin model when attempting to predict percutaneous absorption in humans, in particular for solid lipophilic molecules.

\section{Acknowledgments}

The authors would like to thank Dr Gosset for providing human skin samples, and Marie-Joseph Décret for her help with rat handling and husbandry. 


\section{References:}

Bader M, Wrbitzky R, Blaszkewicz M, Schäper M, van Thriel C. Human volunteer study on the inhalation and dermal absorption of N-methyl-2-pyrrolidone (NMP) from the vapour phase. Arch Toxicol, 2008, 82:13-20.

Bronaugh RL, Stewart RF, Congdon ER. Methods for in vitro percutaneous absorption studies. II. Animal models for human skin. Toxicol Appl Pharmacol, 1982, 62(3):481-8.

Champmartin C., Marquet F., Beydon D., Ferrari E., Grandclaude MC, Payan JP. Artificial sebum as a vehicle for studying ex vivo percutaneous absorption of solid and lipophilic industrial toxicants. March 2016 15th International Conference Perspectives in Percutaneous Penetration.

Godin B, Touitou E. Transdermal skin delivery: predictions for human from in vivo, ex vivo and animal models. Adv Drug Deli Rev, 2007, 59:1152-1161.

Grubauer G, Feingold K, Elias P. Relationship of epidermal lipogenesis to cutaneous barrier function. J Lipid Res, 1987, 28:746-752.

Guth K, Schäfer-Korting M, Fabian E, Landsiedel R, Van ravenzwaay B. Suitability of skin tests for dermal absorption studies in vitro. Toxicol in vitro, 2015, 29:113-123.

Jung CE, Maibach H. Animal models for percutaneous absorption. J Appl Toxicol, 2015, 35:110 .

Kottner J, Lichterfeld A, Blume-Peytavi U. Transepidermal water loss in young and aged healthy huamns: a systematic review and meta-analysis. Arc Dermatol Res; 2013, 305:315-323.

McGrath JA, Eady RAJ, Pope FM. Anatomy and organization of human skin. In: Burns T, Breathnach S, Cox N, Griffiths C, eds. Rook's Textbook of Dermatology, 7th ed. UK: Oxford Blackwell Science; 2004. p. 3-8.

Mizutani Y., Mitsutake S., Tsuji K, Kihara A, Igarashi Y. Ceramide biosynthesis in keratinocyte and its role in skin function. Biochimie, 2009, 91:784-790.

OECD. Skin absorption: in vitro method. OECD guideline for the testing of chemicals, 2004, 428. OECD. Guidance document for the conduct of skin absorption studies. OECD Environmental Health and Safety Publications Series on Testing and Assessment, 2004, 28.

OECD. Guidance notes on dermal absorption. OECD environment, Health and Safety Publications, Series on Testing and Assessment, N 156, 2011.

Payan JP, Beydon D, Fabry JP, Boudry I, Cossec B, Ferrari E. Toxicokinetics and metabolism of $\mathrm{N}-\left[{ }^{14} \mathrm{C}\right] \mathrm{N}$-methyl-2-pyrrolidone in male Sprague-Dawley rats: a saturable NMP elimination process. Drug Metab Dispos, 2002, 30:1418-1424.

Payan JP, Boudry I, Beydon D, Fabry JP, Grandclaude MC, Ferrari E, André JC. Toxicokinetics and metabolism of $\left[{ }^{14} \mathrm{C}\right]-\mathrm{N}$-methyl-2-pyrrolidone in male Sprague-Dawley rats: in vivo and in vitro percutaneous absorption. Drug Metab Dispos, 2003, 31:659-669. 
Pham QD, Björklund S, Engblom J, Topgaard D, Sparr E. Chemical penetration enhancers in stratum corneum - Relation between molecular effects and barrier function. J Control Release, 2016, 232:175-187.

Schneider M, Stracke F, Hansen S, Schaefer UF. Nanoparticles and their interactions with the dermal barrier. Dermatoendocrinol, 2009, 1:197-206.

Todo H. Transdermal permeation of drugs in various animal species. Pharmaceutics 2017, 9, 33.

Conflicts of interest: All the experiments performed in this study were funded by INRS. The authors declare no conflict of interest. 